\title{
Vegy Slime
}

Marta C. Corvo

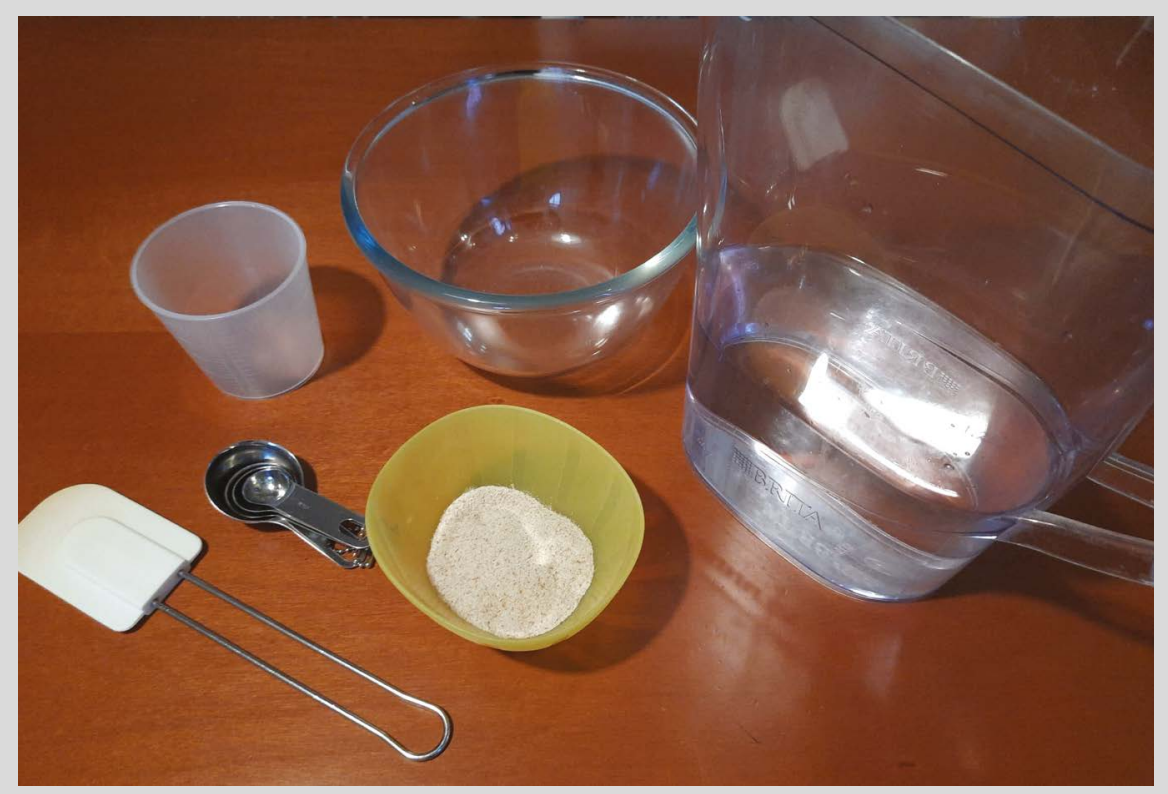

\section{Introdução}

Esta atividade apresenta uma alternativa para a preparação de slime, a substância viscosa que faz as delícias dos mais novos. A maioria das preparações existentes utiliza algumas substâncias com toxicidade considerável. 0 slime aqui proposto é obtido a partir de substâncias não tóxicas, de grau alimentar.

\section{Material}

- Pó de psílio

- Água

- Colher de medida

- Copo de medida

- Espátula

- Recipiente adequado ao micro-ondas

Atenção: Esta experiência requer a supervisão de um adulto. 0 pó de psílio ou Psyllium pode ser encontrado em supermercados e ervanárias. Esta substância não é tóxica, mas como qualquer produto alimentar poderá causar alergias.

\section{Procedimento}

Transferir $200 \mathrm{~mL}$ de água para um

recipiente. 


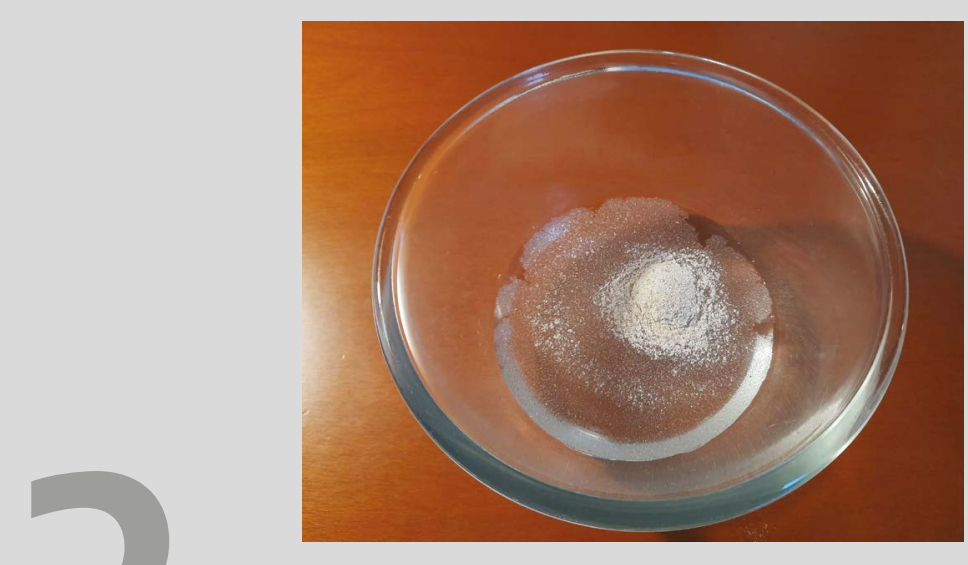

Adicionar uma colher de chá de pó de psílio e misturar com a espátula.
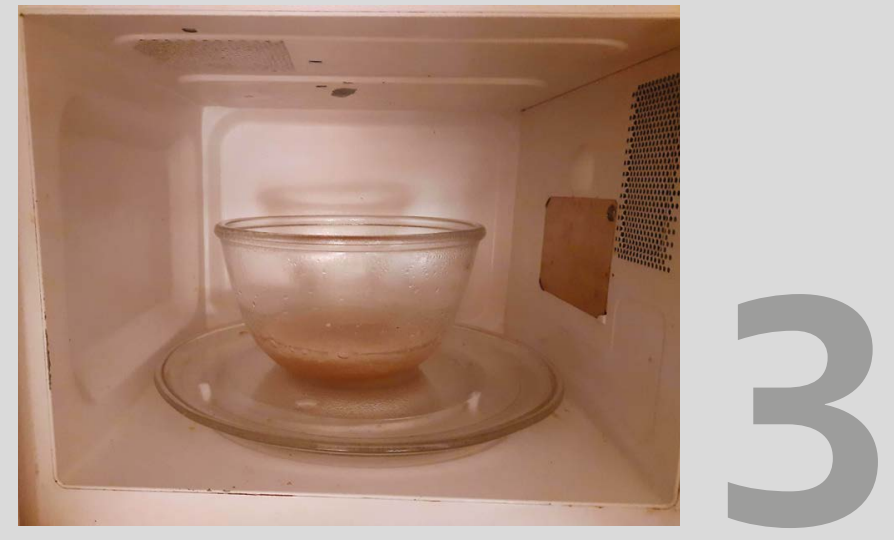

Levar o recipiente ao micro-ondas na potência média. Quando começar a borbulhar, interromper o aquecimento para que acalme, e retomar novamente até perfazer 5 minutos de aquecimento.
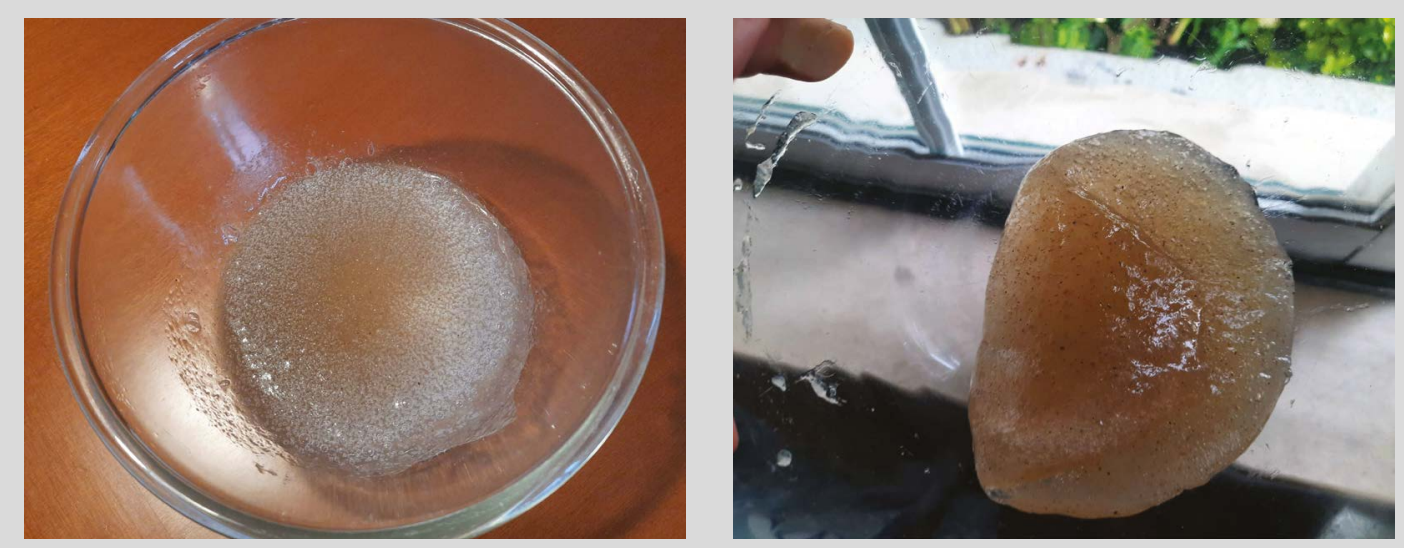

Esperar que arrefeça (cerca de 30 minutos). 


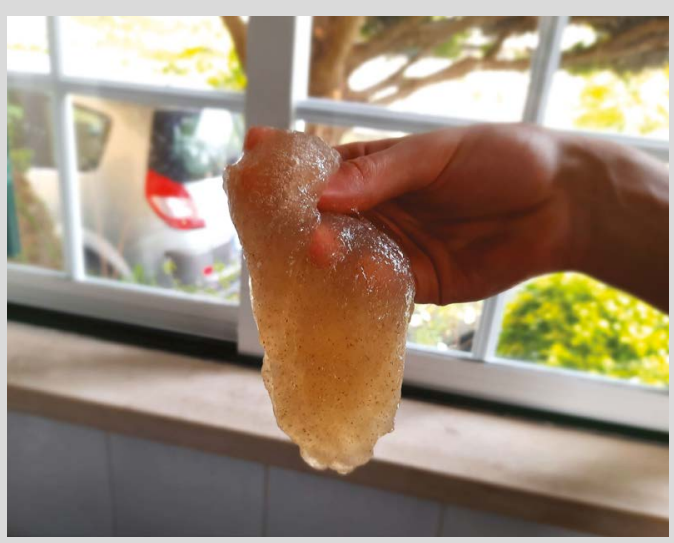

\section{Explicação}

O psílio (psyllium) é uma planta do género Plantago cujas sementes são utilizadas comercialmente como fibras dietéticas e que podem ser usadas como espessante alimentar. A casca destas sementes contém polímeros - substâncias constituídas por unidades mais pequenas, os monómeros, que se repetem e estão ligados entre si formando cadeias. Os polímeros das cascas da semente do psílio são polissacarídeos que conseguem absorver uma grande quantidade de água e aumentam de volume. Na presente atividade, o vegy slime foi obtido ao misturar a água com o pó de psílio. A substância viscosa que se formou é composta por uma suspensão de um líquido (água) disperso num sólido (partículas de casca de psílio). 0 aquecimento no micro-ondas tornou mais rápida a dispersão. Nesta preparação podem ser utilizados corantes alimentares (adicionados na água antes da adição do pó de psílio).

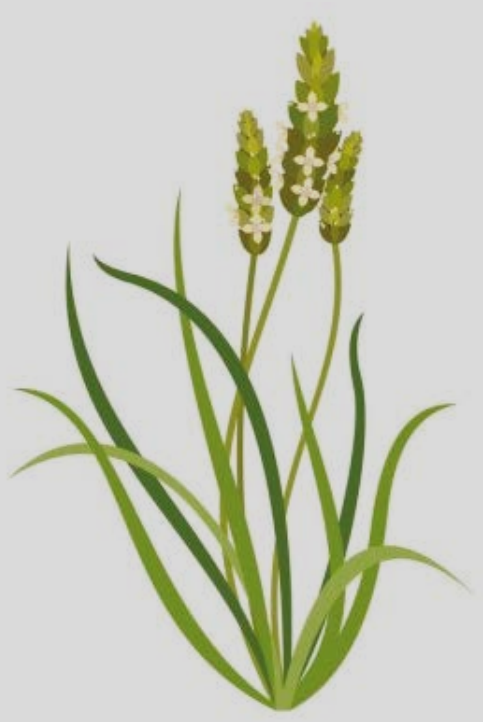

\section{Referências}

[1] Adaptado de: onelittleproject.com/two-ingredient-metamucil-slime (acedido em 20/03/2021).

\section{Marta C. Corvo}

Faculdade de Ciências e Tecnologia, Universidade Nova de Lisboa.

clear. Além da divulgaç̧ão de ciência, É investigadora no i3N|CENIMAT, Dep. Ciência dos Materiais da Faculdade de Ciências e Tecnologia da Universidade NOVA de Lisboa, dedicada à ressonância magnética nuinteressa-se pelo desenvolvimento de novos materiais para captura de $\mathrm{CO}_{2}$, armazenamento de energia e preservação de obras de arte. marta.corvo@fct.unl.pt ORCID.org/0000-0003-0890-6133 